\title{
RESEÑA
}

\section{"Peligro amarillo". La sombra de Japón durante la Revolución Mexicana, de Víctor Kerber Palma}

DOI: $10.32870 /$ mycp.v11i31.800

Héctor Palacios ${ }^{1}$

"PELIGRO AMARILLO"

LA SOMBRI DE JIPOII

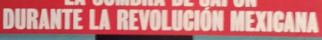

(4)

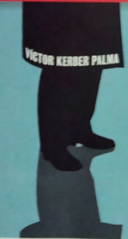

Kerber Palma, Víctor. (2021). "Peligro amarillo". La sombra de Japón durante la Revolución Mexicana. México: Secretaría de Relaciones Exteriores, Dirección General del Acervo Histórico Diplomático, 400 pp.

"Peligro amarillo", con sus puntuales comillas. No se puede y no se debe escribir de otra manera. Siempre debe estar ese entrecomillado. Quien le quite las comillas, probablemente sea el verdadero peligro, o como se dice recientemente en redes sociales, "red flag" o bandera roja a esa persona o personas.

"Peligro amarillo" es una expresión racista, que como bien nos explica Víctor Kerber en su libro, nace en el justo apogeo del darwinismo social, donde el discurso de la superioridad e inferioridad de las razas era el pan de cada día, principalmente en los blancos círculos privilegiados de Europa y Estados Unidos.

La palabra "peligro" se detonó en la mente de las potencias occidentales en el año de 1905, cuando Japón venció a Rusia en la Guerra Ruso-Japonesa. Pero había que ponerle color a ese supuesto "peligro", para que esas mentes paranoicas lo pudieran procesar conforme a su comprensión reduccionista del mundo. Le llamaron "amarillo", entonces, en alusión al color de piel; una alusión, por cierto, muy forzada e imaginativa (sabemos que los estadounidenses repetirán esta expresión despectiva en el marco de la guerra contra Corea, y, no se diga, en el de la Guerra de Vietnam, como el propio cine hollywoodense da cuenta).

1. Investigador independiente, Guadalajara, Jalisco, México. ORCID: https://orcid.org/00000002-1429-3081. Correo electrónico: hpalaciosgdl@gmail.com 
Precisamente, en la historia que nos cuenta este libro, los Estados Unidos están en escena con un rol protagónico, haciendo mal tercio en una narración que, en el mundo de "los hubiera", hubiéramos querido que fuera una historia nada más de dos: México y Japón, Japón y México, pero no fue así. Al vecino atento y vigilante no le parecía esta amistad nacida formalmente en 1888. Ello a pesar de que las negociaciones del Tratado de Amistad, Comercio y Navegación de México y Japón se realizaron en Washington. De lo cual nos habla Víctor Kerber en el capítulo II del libro, con la participación destacada del diplomático Matías Romero, o, como opta Kerber por llamarlo como recurso narrativo: Don Matías.

En este mismo capítulo, el autor dedica varias páginas a la historia de la colonia japonesa que se estableció en el Soconusco chiapaneco a finales del siglo XIX; una historia terrible en sus inicios, pero en términos generales con un giro feliz, si se me permite utilizar dicho término, no del todo preciso. Sobre este tema en específico, el libro aporta nuevos detalles, principalmente sobre los hechos previos que propiciaron el envío de japoneses a Chiapas.

La primera década del siglo $\mathrm{xx}$, en el apogeo del Porfiriato, fue la época de oro de la migración japonesa a México, además de vivirse una especie de japonofilia entre las clases altas y medias de este país (admiración que creció con el triunfo militar de Japón sobre la Rusia zarista, todo lo opuesto al pánico en el que entraron las potencias occidentales). Fue durante esos años que varias familias adineradas incorporaban tibores japoneses como parte de la decoración de sus residencias. El mismo don Porfirio tenía una armadura samurai ceremonial del siglo XVII y un sable con una funda preciosa del marfil, del siglo XVIII, que formaban parte de su colección particular de armas. Estas piezas, afortunadamente, se pueden apreciar en el Museo del Ejército, en la sede de la ciudad de Guadalajara.

Esta japonofilia alcanzó un punto máximo durante las fiestas del Centenario, como nos lo cuenta Kerber en el capítulo III. Donde la cercanía y afinidad de la legación japonesa con el Presidente Díaz era notable y notoria. El mismo pueblo era partícipe de esto. El autor nos narra cómo, durante el desfile de los contingentes militares de varias partes de mundo, los japoneses fueron ampliamente vitoreados y aplaudidos, mientras que los estadounidenses, que confirmaron su participación de último momento, fueron vistos con frialdad, e incluso se llevaron algunos abucheos. Desde luego, todo esto abonó a las paranoias estadounidenses, y prendía esos focos rojos llamados Doctrina Monroe. Y es aquí donde el autor del libro lanza una afirmación a 
tomarse en cuenta: el factor de la cercanísima relación entre México y Japón, como una causa más del hundimiento de Díaz en 1911. No ahondaré en dicha premisa, para que el propio lector descubra los detalles de la argumentación de Kerber al respecto.

El capítulo IV lo dedica a la relación del maderismo con Japón. Si con la salida de Díaz, los Estados Unidos veían una nueva oportunidad de asentar sin contrapesos la Doctrina Monroe en México, estaban equivocados: el maderismo bebía también de la japonofilia. Desde luego, los estadounidenses promotores del "peligro amarillo" no lo podían comprender, incluido el embajador Henry Lane Wilson, quien mucho tuvo que ver en el golpe de estado contra Francisco I. Madero. Es aquí donde Víctor Kerber aborda los hechos de la Decena Trágica, cuya narración, a más de 100 años de distancia, aún conmueve, y en los que la legación japonesa e inmigrantes japoneses voluntarios tuvieron un rol sumamente activo, defendiendo la vida de los familiares del Presidente Madero.

Mientras uno avanza por las páginas del libro, va quedando claro que esa paranoia llamada "peligro amarillo" no aplicaba al entorno social mexicano (como sí ocurría en la sociedad estadounidense, en especial en California). Pero sí rondaba por los pasillos diplomáticos a través de los miedos y odios infundados de Estados Unidos y de las difamaciones premeditadas de Alemania (en el preludio de la Primera Guerra Mundial).

En el capítulo $v$ podemos conocer detalles de las relaciones entre Japón y el gobierno espurio de Victoriano Huerta. Y recuerden, en esta historia siempre están los Estados Unidos como mal tercio. Si en un principio Washington apoyó al golpista Huerta, pronto se desencantaron al ver que era alguien que no podrían controlar como ellos se lo imaginaban. Entonces le retiraron su apoyo, y fue cuando Huerta se acercó a Japón, pues requería de armas para hacer frente a los ejércitos revolucionarios: nos habla Kerber de que hubo negociaciones de al menos 50,000 rifles y cuatro millones de cartuchos fabricados por la compañía japonesa Mitsui. De eso se concretó solo una parte, pero es un dato que importa para entender mejor la existencia del factor japonés durante la Revolución Mexicana, hasta ahora poco o nada considerado por los historiadores. Por cierto, sobre la compañía Mitsui, fabricante de armas en aquel entonces, es hoy en día mejor conocida por su producción actual de televisiones y demás accesorios de audio y video.

Si buena parte de esas armas japonesas negociadas por Huerta no llegaron a México, fue en gran medida por la contrainteligencia de los carrancistas. Por 
lo que el dolor de cabeza de Washington continuaría: las relaciones de Japón con los gobernantes mexicanos seguirían siendo cercanas, sin importar bando o ideología. Esto, sumado a las manifestaciones projaponesas de la gente de a pie, como ocurrió con la llegada de los representantes de aquel país en 1910 para las celebraciones del Centenario, o con la llegada del nuevo embajador, Adachi Mineichiro, en el verano de 1913, o las manifestaciones de júbilo que hubo por el reconocimiento oficial de Japón al gobierno de Venustiano Carranza, en 1916. Justo el capítulo VI trata el periodo del gobierno carrancista.

Sobre la llegada del embajador Adachi, nos cuenta Víctor Kerber que: "En Guadalajara, una multitud lo vitoreó y el alcalde de la ciudad lo designó como visitante distinguido...". Será oportuno acudir más adelante al Archivo Municipal de Guadalajara, para consultar las actas de cabildo de ese año, donde seguro hay constancia detallada de esta recepción especial que recibió el embajador Adachi en julio de 1913.

Vale decir aquí, que este libro, además de conocer la temática específica que planteó Kerber en su investigación, es también un repaso de contextos históricos más amplios, y que eran necesarios de abordar para la mejor comprensión del hilo argumentativo. El propio autor, en la página 318 del libro, nos hace una descripción puntual acerca de este trabajo:

No ha sido la pretensión de esta obra descubrir algún hilo negro sobre la Revolución Mexicana, ni tampoco elaborar un panegírico sobre las estupendas relaciones entre Japón y México. Sí, en cambio, se han querido introducir algunos elementos novedosos que ayudarán a comprender mejor las relaciones de México durante la etapa revolucionaria. Las posturas políticas de Estados Unidos con respecto a México, entre 1905 y 1925, no se comprenderían a cabalidad sin el factor Japón, en eso radica la originalidad de nuestro enfoque. Japón aparece aquí como un elemento que sin duda afectó las sensiblerías, al suponerse que reiteradamente conjuraba contra los intereses estratégicos de los norteamericanos dentro de lo que éstos consideraban como su patio trasero.

Una presencia constante a lo largo de los capítulos de este libro, es la paranoia fastidiosa de Estados Unidos, dotada de una buena dosis de racismo; es así como se llega a la década de 1920, que plantea Kerber de la siguiente manera:

En Estados Unidos, al "peligro amarillo" se le sumaron otras tantas paranoias, como la amenaza bolchevique contra el capitalismo, el supuesto complot judío 
con alcances mundiales, e incluso la eventual invasión de mexicanos liderados por el temible Pancho Villa.

El libro cierra con el séptimo capítulo, al que Kerber tituló: "Epílogo. Triunfo de Monroe", donde brevemente da un salto a ese quiebre de la amistad entre Japón y México, con la Segunda Guerra Mundial, y la reclusión y despojo de los residentes japoneses ocurrida en nuestro país, lo cual, hasta la fecha parece vergonzoso que el gobierno mexicano se haya prestado a eso, pero también, hay que decirlo, fue algo a lo que los inmigrantes japoneses, de manera admirable, se supieron sobreponer, al igual que las relaciones entre México y Japón, que retomaron su curso de amistad en la década de 1950.

Por último, manifiesto que este es ya un libro obligatorio para aquellos que quieran desarrollar nuevas investigaciones sobre las relaciones México-Japón, así como investigaciones sobre migración japonesa a México. Felicidades al autor por esta aportación a la historiografía mexicana. 